\title{
Hsp90 modulates human sperm capacitation via the Erk1/2 and p38 MAPK signaling pathways
}

\author{
Peibei Sun ${ }^{\dagger}$, Yayan Wang ${ }^{\dagger}$, Tian Gao, Kun Li, Dongwang Zheng, Ajuan Liu and Ya Ni
}

\begin{abstract}
Background: Heat shock protein 90 (Hsp90) is a highly abundant eukaryotic molecular chaperone that plays important roles in client protein maturation, protein folding and degradation, and signal transduction. Previously, we found that both Hsp90 and its co-chaperone cell division cycle protein 37 (Cdc37) were expressed in human sperm. Hsp90 is known to be involved in human sperm capacitation via unknown underlying mechanism(s). As Cdc37 was a kinase-specific co-chaperone of Hsp90, Hsp90 may regulate human sperm capacitation via other kinases. It has been reported that two major mitogen-activated protein kinases (MAPKs), extracellular signalregulated kinase 1/2 (Erk1/2) and p38, are expressed in human sperm in the same locations as Hsp90 and Cdc37. Phosphorylated Erk1/2 has been shown to promote sperm hyperactivated motility and acrosome reaction, while phosphorylated p38 inhibits sperm motility. Therefore, in this study we explored whether Hsp90 modulates human sperm capacitation via the Erk1/2 and p38 MAPK signaling pathways.
\end{abstract}

Methods: Human sperm was treated with the Hsp90-specific inhibitor 17-allylamino-17-demethoxygeldanamycin (17-AAG) during capacitation. Computer-assisted sperm analyzer (CASA) was used to detect sperm motility and hyperactivation. The sperm acrosome reaction was analyzed by using fluorescein isothiocyanate-conjugated Pisum sativum agglutinin (PSA-FITC) staining. The interactions between Hsp90, Cdc37, Erk1/2 and p38 were assessed using co-immunoprecipitation (Co-IP) experiments. Western blotting analysis was used to evaluate the levels of protein expression and phosphorylation.

Results: Human sperm hyperactivation and acrosome reaction were inhibited by 17-AAG, suggesting that Hsp90 is involved in human sperm capacitation. In addition, Co-IP experiments revealed that 17-AAG reduced the interaction between Hsp90 and Cdc37, leading to the dissociation of Erk1/2 from the Hsp90-Cdc37 protein complex. Western blotting analysis revealed that levels of Erk1/2 and its phosphorylated form were subsequently decreased. Decreasing of Hsp90-Cdc37 complex also affected the interaction between Hsp90 and p38. Nevertheless, p38 dissociated from the Hsp90 protein complex and was activated by autophosphorylation.

(Continued on next page)

\footnotetext{
* Correspondence: niya99@126.com

${ }^{\dagger}$ Peibei Sun and Yayan Wang contributed equally to this work. Department of Reproductive Physiology, Zhejiang Academy of Medical Sciences / Hangzhou Medical College, 310013 Hangzhou, Zhejiang, China
}

(C) The Author(s). 2021 Open Access This article is licensed under a Creative Commons Attribution 4.0 International License, which permits use, sharing, adaptation, distribution and reproduction in any medium or format, as long as you give appropriate credit to the original author(s) and the source, provide a link to the Creative Commons licence, and indicate if changes were made. The images or other third party material in this article are included in the article's Creative Commons licence, unless indicated otherwise in a credit line to the material. If material is not included in the article's Creative Commons licence and your intended use is not permitted by statutory regulation or exceeds the permitted use, you will need to obtain permission directly from the copyright holder. To view a copy of this licence, visit http://creativecommons.org/licenses/by/4.0/. The Creative Commons Public Domain Dedication waiver (http://creativecommons.org/publicdomain/zero/1.0/) applies to the data made available in this article, unless otherwise stated in a credit line to the data. 
(Continued from previous page)

Conclusions: Taken together, our findings indicate that Hsp90 is involved in human sperm hyperactivation and acrosome reaction. In particular, Hsp90 and its co-chaperone Cdc37 form a protein complex with Erk1/2 and p38 to regulate their kinase activity. These results suggest that Hsp90 regulates human sperm capacitation via the Erk1/2 and p38 MAPK signaling pathways.

Keywords: Sperm capacitation, Hsp90, Erk1/2, P38, MAPK signaling pathway, Phosphorylation

\section{Background}

Spermatozoa that have just been ejaculated cannot fertilize oocytes and must undergo a series of biochemical and physiological events in the female reproductive tract to become fertilization competent. This process is known as sperm capacitation [1]. Capacitated sperm usually exhibit protein tyrosine phosphorylation, hyperactivated motility, and acrosome reaction initiation [2], which aids the fusion of sperm into an oocyte. It is generally known that sperm capacitation starts from outflow of cholesterol in the plasma membrane and subsequently increases the permeability of membrane [3]. The increasing influx of $\mathrm{Ca}^{2+}$ and $\mathrm{HCO}_{3}{ }^{-}$activated soluble adenylate cyclase (sAC) [4-6], which catalyzes the conversion of ATP into cAMP. Subsequently, cAMP activates cAMP-dependent protein kinase A (PKA), which activates target proteins and promotes protein tyrosine phosphorylation [7]. However, the mechanisms that act downstream of PKA during human sperm capacitation remain unclear.

Heat shock protein 90 (Hsp90) is a highly abundant eukaryotic molecular chaperone that plays important roles in various aspects of cell physiology, including client protein maturation, protein folding and degradation, signal transduction, and the assembly of multiprotein complexes [8-10]. Recently, Zierer et al. demonstrated that Hsp90 plays a key role in the activation of various client proteins at the center of cell signaling [11]. Previously, we found that Hsp90 is expressed predominantly in the neck, midpiece, and tail regions of human sperm [12]. Geldanamycin is a specific Hsp90 inhibitor that has been shown to interrupt human sperm capacitation, change protein tyrosine phosphorylation levels, and decrease hyperactivated motility and acrosome reaction. In addition, other studies have found that Hsp90 levels are downregulated in oligoasthenozoospermia and that the functional inhibition of Hsp90 can attenuate progesterone-mediated sperm motility and acrosome reaction $[12,13]$. However, the underlying mechanisms remain unknown.

Cell division cycle 37 (Cdc37) is an important kinasespecific co-chaperone of Hsp90 that plays a crucial role in the maturation of numerous kinases by acting as an adapter and loading them onto the Hsp90 complex [14, 15]. In somatic cells, Cdc37 has been shown to bind to kinases during or shortly after translation and recruit them to the Hsp90 protein complex, thereby protecting the kinases from proteasomal degradation and maintaining their activity [16-19]. Recently, we demonstrated that Cdc37 is expressed in the neck and tail regions of human sperm, which also contain Hsp90, suggesting that these proteins may interact to regulate kinases activity during human sperm capacitation [20]. Many kinases regulate sperm function via protein phosphorylation with the help of Hsp90; for instance, PKA and protein kinase C (PKC) phosphorylate Hsp90 in sperm, which regulates non-receptor tyrosine kinase Src during capacitation [20].

Mitogen-activated protein kinases (MAPK) cascades play a pivotal role in signal transduction during many cellular responses, including metazoan development, differentiation, survival, migration, proliferation, growth, and apoptosis [21, 22]. The mammalian MAPK cascade consists of three major tiers of protein kinases, namely MAP kinase kinase kinases (MAP3Ks), MAP kinase kinases (MAP2Ks) and MAPKs, which can be activated in turn to phosphorylate downstream effectors, such as transcription factors, and affect cell differentiation, cell motility, cell death and intracellular trafficking [23]. There are at least three MAPK protein families, including extracellular signal-regulated kinase 1/2 (Erk1/2), p38, and c-Jun N-terminal kinases 1-3 (JNK1-3) [21], and many of proteins in the MAPK pathway interact with Hsp90 [24-26]. Erk1/2 and p38, but not JNK1/2, have been detected in the tail region of mature human sperm [27], consistent with Hsp90 and Cdc37. In addition, many studies have shown that Erk1/2 and p38 are involved in regulating sperm motility: phosphorylated Erk1/2 promotes sperm motility and hyperactivated motility, whereas phosphorylated p38 inhibits sperm motility [28]. Both Erk1/2 and p38 play positive roles in acrosome reaction [29], suggesting that the MAPK pathway may regulating capacitation and acrosome reaction in the female reproductive tract before fertilization.

Since the proteins in MAPK cascades are all kinases, we explored whether Hsp90 and its kinase-specific cochaperone $\mathrm{Cdc} 37$ regulate the MAPK pathway during human sperm capacitation. The findings of this study will help us to understand the mechanisms via which Hsp90 regulates sperm capacitation. 


\section{Materials and methods}

\section{Chemicals and reagents}

Percoll was purchased from GE Healthcare BioSciences AB (Uppsala, Sweden). Sodium dodecyl sulfate lysis buffer (used for western blotting, P0013G), cell lysis buffer (used for Co-immunoprecipitation (Co-IP), P0013), and all other reagents for sodium dodecyl sulfatepolyacrylamide gel electrophoresis (SDS-PAGE) and western blotting were acquired from the Beyotime Institution of Biotechnology (Shanghai, China). Protein loading buffer, ECL plus chemiluminescence kit, and pre-dyed protein marker were purchased from Thermo Fisher Scientific Inc. (Burlington, NC, USA). Protein $A+G$ agarose was obtained from Santa Cruz Biotechnology Inc. (Dallas, Texas, USA). Progesterone and fluorescein isothiocyanate-conjugated Pisum sativum agglutinin (PSA-FITC) were purchased from Sigma-Aldrich (St Louis, MO, USA). Dimethyl sulfoxide (DMSO) was obtained from Merck (Darmstadt, Germany). 17allylamino-17-demethoxygeldanamycin (17-AAG) was provided by Cell Signaling Technology (Danvers, MA, USA). Complete Mini EDTA-free Protease Inhibitor Cocktail and Phosphatase Inhibitor Cocktail were obtained from Roche (Mannheim, Germany). Mouse monoclonal anti-Erk1/2 antibody (SC514302), mouse monoclonal anti-p-Erk1/2 (phosphor T202/185 and Y204/ 187) antibody (SC81492), and anti-Cdc37 antibody (SC13129) were purchased from Santa Cruz Biotechnology Inc; Rabbit monoclonal anti-p38 antibody (ab170099), rabbit polyclonal anti-p-p38 (phosphor T180 and Y182) antibody (ab4822), rabbit monoclonal antiHsp90 antibody (ab203126) and rabbit anti- $\beta$-tubulin antibody (ab6046) were purchased from Abcam (Cambridge, UK). Horseradish peroxidase (HRP)-conjugated goat antirabbit and goat anti-mouse IgG were purchased from Invitrogen (Carlsbad, CA, USA).

\section{Human tubal fluid (HTF) medium}

HTF medium was prepared as described previously [20]. It was used throughout the study for sperm treatment and consisted of $90 \mathrm{mM} \mathrm{NaCl}, 5.06 \mathrm{mM} \mathrm{KCl}, 1.80 \mathrm{mM}$ $\mathrm{CaCl}_{2}, 25.3 \mathrm{mM} \mathrm{NaHCO}, 1.01 \mathrm{mM} \mathrm{MgSO} 4,1.17 \mathrm{mM}$ $\mathrm{KH}_{2} \mathrm{PO}_{4}, 5.56 \mathrm{mM}$ glucose, $21.6 \mathrm{mM}$ sodium lactate, $0.27 \mathrm{mM}$ sodium pyruvate, $20 \mathrm{mM}$ Hepes, $4 \mathrm{~g} / \mathrm{L}$ bovine serum alubm (BSA), $60 \mathrm{mg} / \mathrm{L}$ penicillin, and $5 \mathrm{mg} / \mathrm{L}$ phenol red. The $\mathrm{pH}$ of the medium was adjusted to 7.4 by using sodium hydroxide $(\mathrm{NaOH})$ or hydrochloric acid $(\mathrm{HCl})$. All chemicals mentioned here were provided by Sigma-Aldrich.

\section{Semen collection and sperm treatment}

This study was approved by the Medical Ethics Committee of the Zhejiang Academy of Medical Sciences. Informed consents were obtained prior to semen sample collection form healthy male donors (25 to 35 years old). Fresh semen samples were obtained by masturbation after sexual abstinence for 3-5 days, and liquefied for $1 \mathrm{~h}$ at $37^{\circ} \mathrm{C}$ for subsequent processing. According to World Health Organization (WHO) requirements, sperm samples in this study met the following criteria: sperm motility $\geq 50 \%$, sperm viability $\geq 85 \%$, sperm concentration $\geq 20 \times 10^{6}$ sperm $/ \mathrm{mL}$, and morphologically normal sperm $\geq 15 \%$. Semen was centrifuged with $40 \%$ and $80 \%$ discontinuous Percoll gradients at $750 \times g$ for $15 \mathrm{~min}$ to remove dead sperm and cell debris. The precipitate was resuspended in HTF medium, centrifuged at $500 \times g$ for $5 \mathrm{~min}$, and adjusted to a density of approximately $20 \times 10^{6}$ sperm $/ \mathrm{mL}$ in HTF supplemented with $2.5 \mu \mathrm{M}$ progesterone. The sperm was divided into aliquots treated with different concentration of 17-AAG (0.5 $\mu \mathrm{M}$ or $5 \mu \mathrm{M}$, DMSO as vehicle control), and cultured in a $5 \% \mathrm{CO}_{2}$ incubator at $37^{\circ} \mathrm{C}$ in constant humidity for $3 \mathrm{~h}$.

\section{Assessment of sperm capacitation}

Since only capacitated sperm undergo exocytosis, human sperm capacitation was evaluated indirectly using a progesterone-induced acrosome reaction. According to the WHO Laboratory Manual for the Examination and Processing of Human Semen (5th ed), the acrosome reaction was assessed by PSA-FITC staining. Following capacitation culture, sperm were fixed with $95 \%$ ethanol for $30 \mathrm{~min}$, mounted on Silane-Prep slides, and then air dried and incubated overnight in the dark at $4{ }^{\circ} \mathrm{C}$ with $25 \mathrm{mg} / \mathrm{L}$ PSA-FITC. Sperm were washed with PBS and examined by fluorescence microscopy $(n>200$ sperm/ sample) (Nikon Eclipse 80i; Nikon Inc., Tokyo, Japan).

\section{Sperm motility and hyperactivation analysis}

Sperm motility and hyperactivation were analyzed using a computer-assisted sperm analyzer (CASA; IVOS, Hamilton-Thorne Bio-Sciences, Beverly, MA, USA) with the following parameters: frame rate, $60 \mathrm{~Hz}$; acquisition frame, 30; minimum contrast, 80; minimum cell size, 3 pixels; cell intensity, 40; path velocity, $25.0 \mu \mathrm{m} / \mathrm{s}$; straightness threshold, $80 \%$; slow cell, average path velocity (VAP) and straight line velocity (VSL) of less than $5.0 \mu \mathrm{m} / \mathrm{s}$ and $11 \mu \mathrm{m} / \mathrm{s}$, respectively; illumination intensity, 2164; magnification, $1.73 \times$; temperature, $37{ }^{\circ} \mathrm{C}$; and chamber depth, $20 \mu \mathrm{m}$ ( $n>200$ motile sperm per sample). Briefly, sperm samples $(5 \mu \mathrm{L})$ were loaded into 20 $\mu \mathrm{m}$ deep of slides chambers warmed to $37{ }^{\circ} \mathrm{C}$ and the following parameters were assessed: VSL, VAP, curvilinear velocity $(\mathrm{VCL})$, straightness $(\mathrm{STR}=\mathrm{VSL} / \mathrm{VAP} \times 100)$, linearity (LIN $=$ VSL/VCL $\times 100)$, amplitude of lateral head displacement (ALH), beat-cross frequency (BCF), and the percentage of motile, progressive, and hyperactivated sperm. Sperm hyperactivation was defined using 
the SORT function as follows: VCL $\geq 150 \mu \mathrm{m} / \mathrm{s} ; \mathrm{ALH} \geq$ $7.0 \mu \mathrm{m}$; and $\mathrm{LIN} \leq 50 \%$.

\section{Protein extraction}

According to our previously reported method, sperm were washed twice with PBS and resuspended in lysis buffer containing protease inhibitors (Complete Mini EDTA-free Protease Inhibitor Cocktail and Phosphatase Inhibitor Cocktail) and $1 \mathrm{mM}$ phenylmethylsulfonyl fluoride (PMSF). After ultrasonication, the samples were centrifuged at $14,000 \times g$ for $20 \mathrm{~min}$ and the supernatant was collected. Protein concentration was determined using a bicinchoninic acid (BCA) assay kit (Beyotime Institution of Biotechnology).

\section{Co-IP experiments}

For Co-IP, sperm protein was extracted by ultrasonication in lysis buffer supplemented with $20 \mathrm{mM}$ sodium molybdate $\left(\mathrm{Na}_{2} \mathrm{MoO}_{4}\right), 1 \%$ Nonidet P-40 (NP-40), 1 mM PMSF, Roche Complete Mini EDTA-free Protease Inhibitor Cocktail, and Phosphatase Inhibitor Cocktail. Approximately $500 \mu \mathrm{g}$ of protein lysate was incubated with $1 \mu \mathrm{g}$ of rabbit or mouse IgG and $20 \mu \mathrm{L}$ protein A + $\mathrm{G}$ agarose beads under rotation for $2 \mathrm{~h}$ at $4{ }^{\circ} \mathrm{C}$ before being centrifuged at $1000 \times g$ for $5 \mathrm{~min}$. Each of the supernatants were mixed with $2 \mu \mathrm{g}$ of anti-Cdc37, antiErk1/2, or anti-p38 antibodies respectively and then incubated under rotation at $4{ }^{\circ} \mathrm{C}$ overnight. Next, $40 \mu \mathrm{L}$ of protein $\mathrm{A}+\mathrm{G}$ agarose beads were added to the mixture and rotated gently for $5 \mathrm{~h}$ to capture the antigenantibody complexes. Precipitates were separated by centrifugation at $1000 \times g$ for $5 \mathrm{~min}$ and the agarose beads were washed five times with lysis buffer, mixed with $5 \times$ loading buffer, and boiled at $100{ }^{\circ} \mathrm{C}$ for $10 \mathrm{~min}$ for electrophoresis preparation.

\section{Western blotting}

Equal amounts of sperm protein $(20 \mu \mathrm{g})$ from different treatment groups or equal agarose beads was denatured by incubation with protein loading buffer at $100^{\circ} \mathrm{C}$ for $10 \mathrm{~min}$ and separated by SDS-PAGE with a pre-stained protein ladder as a molecular weight marker. Proteins were transferred to an Immunoblot-P membrane (Millipore Corporation, Bedford, Massachusetts, USA) which was immersed in $5 \%$ skimmed milk $(\mathrm{m} / \mathrm{v})$ in Tris-buffered saline (TBS; $\mathrm{pH}$ 7.4) for $1 \mathrm{~h}$ at room temperature and incubated with specific antibodies against Erk1/2, phosphor-Erk1/2, p38, phosphor-p38, or $\mathrm{Hsp} 90$ at $4^{\circ} \mathrm{C}$ overnight. After three washes at 5 -min intervals with TBS supplemented with $0.01 \%$ Tween-20 $(\mathrm{v} / \mathrm{v})$, the membranes were incubated with appropriate secondary antibodies at room temperature for $1 \mathrm{~h}$ and washed a further three times. Protein blots were detected using an enhanced chemiluminescence (ECL) kit
(Thermo Fisher Scientific) with a gel imaging system (Amersham Imager 600; General Electric Company, USA). As a loading control, membranes were stripped for probing with $\beta$-tubulin antibodies. Gray intensity was analyzed using Image J software.

\section{Statistical analysis}

Statistical analyses were performed using the Statistical Package for the Social Sciences software (SPSS, version 23; IBM Corporation, Armonk, NY, USA). Data are expressed as the mean \pm standard error of the mean (SEM). One-way analysis of variance was used for statistical analysis. When tests for the homogeneity of variance were significant $(P<0.05)$, data were analyzed using Dunnett's T3 test; otherwise, the least significant difference test was used. All $P$ values were based on two-sided comparisons and values of $<0.05$ were considered statistically significant.

\section{Results}

\section{7-AAG inhibits human sperm capacitation}

Previously, we found that geldanamycin influences human sperm capacitation [12]; therefore, in this study we examined the effect of 17-AAG, a geldanamycin derivative and specific Hsp90 inhibitor, on human sperm capacitation. Since capacitated sperm always display hyperactivated motility and the acrosome reaction, we evaluated the effect of 17-AAG on human sperm capacitation indirectly using acrosome reaction and hyperactivation assays. PSAFITC staining easily distinguished sperm with an acrosome reaction (AR) and those with acrosome integrity (AI) (Fig. 1a). When human sperm was treated with $5 \mu \mathrm{M}$ 17-AAG during capacitation, a significantly low percentage underwent the acrosome reaction than when treated with DMSO (vehicle control; Fig. $1 \mathrm{~b}, P<0.05$ ). When sperm motility and hyperactivation were evaluated using CASA, we found that $5 \mu \mathrm{M}$ 17-AAG markedly decreased sperm hyperactivation (Fig. $1 \mathrm{c}, P<0.05$ ). Detailed sperm motility parameters are summarized in Table 1 . These results are consistent with our previous findings and suggest that Hsp90 plays a role in human sperm capacitation via unknown underlying mechanisms.

\section{7-AAG decreases levels of the Hsp90-Cdc37 protein complex}

Cdc37 is a kinase-specific Hsp90 co-chaperone that recruits kinases to the Hsp90-Cdc37 protein complex to maintain their activity or stability [30]. To determine whether Hsp90 regulates human sperm capacitation by stabilizing Erk1/2 and p38 or activating their kinase activity, we examined the interaction between Hsp90 and Cdc37 during human sperm capacitation firstly, by treating sperm with or without $5 \mu \mathrm{M} 17$-AAG for $3 \mathrm{~h}$, followed by Co-IP. Hsp90 was around $90 \mathrm{kD}$ in size. No 

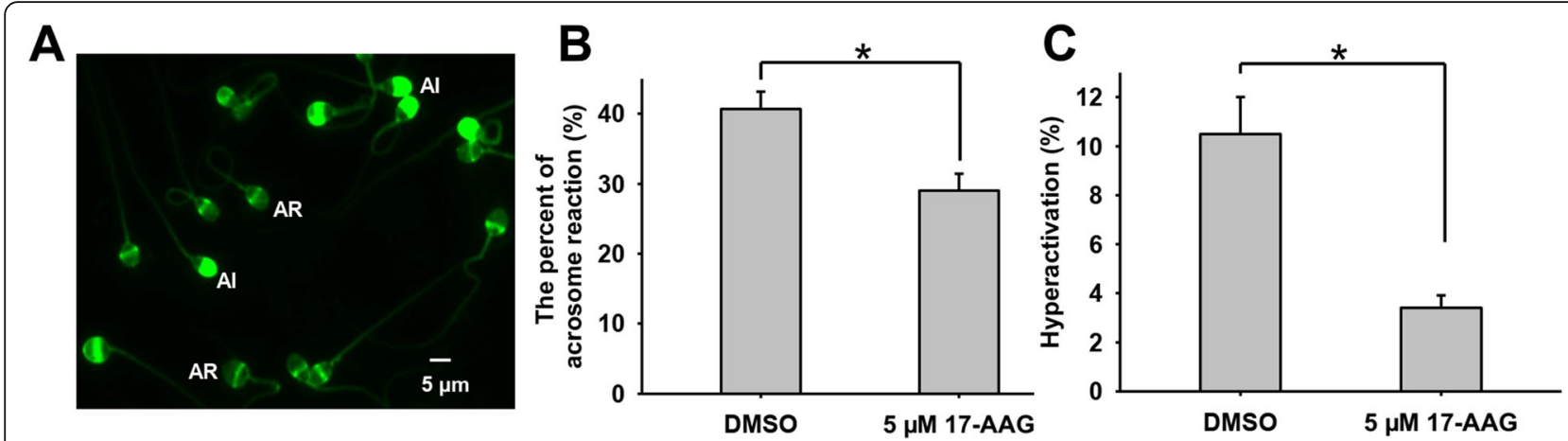

Fig. 1 17-AAG inhibits human sperm acrosome reaction and hyperactivation. a. The human sperm acrosome reaction was evaluated using PSAFITC staining, a common method for assessing sperm capacitation based on alterations in sperm head staining. Acrosome reaction (AR) indicates capacitated and acrosome-reacted sperm, while acrosome integrity (Al) indicates uncapacitated sperm. $\mathbf{b}$. The acrosome reaction percentage was significantly lower when human sperm were treated with $5 \mu$ M 17-AAG than vehicle control $\left({ }^{*} P<0.05\right)$. c. Sperm motility and hyperactivation were analyzed using CASA. The percentage of sperm with hyperactivated motility was significantly lower when treated with $5 \mu \mathrm{M}$ 17-AAG than vehicle control $\left({ }^{*} P<0.05\right)$

interaction was observed between non-immune mouse IgG and Hsp90, whereas a clear interaction was evident between Hsp90 and Cdc37 (Fig. 2a). We also found that the interaction between $\mathrm{Hsp} 90$ and Cdc37 was significantly reduced following treatment with 17-AAG. The relative association between $\mathrm{Hsp} 90$ with $\mathrm{Cdc} 37$ was around $65 \%$ of the control when treated with $5 \mu \mathrm{M} 17$ AAG $(* P<0.05)$ (Fig. $2 b)$, suggesting that levels of the Hsp90-Cdc37 protein complex decreased in the presence of 17-AAG and that kinases bound to Hsp90-Cdc37 may dissociate from the complex.

\section{7-AAG causes Erk1/2 to dissociate from Hsp90 and be degraded}

Erk1/2 is known to be located in the tail regions of human sperm and regulate capacitation [27]; therefore, we

Table 1 Effect of 17-AAG on motility parameters in human sperm

\begin{tabular}{lcc}
\hline & DMSO & $\mathbf{5} \boldsymbol{\mu M} \mathbf{1 7 - A A G}$ \\
\hline Motility (\%) & $62.5 \pm 8.5$ & $51.4 \pm 2.9$ \\
$\operatorname{VSL}(\mu \mathrm{m} / \mathrm{s})$ & $53.5 \pm 4.0$ & $48.6 \pm 1.8$ \\
$\operatorname{VCL}(\mu \mathrm{m} / \mathrm{s})$ & $111.3 \pm 4.5$ & $93.5 \pm 2.4$ \\
$\operatorname{VAP}(\mu \mathrm{m} / \mathrm{s})$ & $64.7 \pm 3.7$ & $57.3 \pm 1.9$ \\
STR $(\%)$ & $80.8 \pm 1.8^{*}$ & $82.2 \pm 0.5^{*}$ \\
LIN $(\%)$ & $48.5 \pm 1.9$ & $52.0 \pm 0.8$ \\
ALH $(\mu \mathrm{m})$ & $4.7 \pm 0.2$ & $4.1 \pm 0.1$ \\
BCF $(\mathrm{Hz})$ & $28.9 \pm 1.2$ & $28.9 \pm 0.4$ \\
Progressive sperm $(\%)$ & $39.8 \pm 5.8^{*}$ & $33.4 \pm 2.6^{*}$ \\
Hyperactivation $(\%)$ & $10.5 \pm 1.5^{*}$ & $3.4 \pm 0.5^{*}$ \\
\hline
\end{tabular}

Results are expressed as means \pm standard error of the mean (SEM; $n=6$ ). The results showed that $5 \mu \mathrm{M}$ 17-AAG significantly inhibited human sperm hyperactivation $(* P<0.05)$. VSL straight line velocity; $V C L$ curvilinear velocity; VAP average path velocity; STR straightness (VSL/VAP multiplied by 100); LIN linearity (VSL/NCL multiplied by 100); ALH amplitude of lateral head displacement; and $B C F$ beat-cross frequency examined the interaction between Hsp90 and Erk1/2 using Co-IP and western blotting. No interaction was observed between the IgG control and Hsp90, yet a clear interaction was evident between Erk1/2 and Hsp90 (Fig. 3a). In addition, 17-AAG significantly decreased the interaction between Hsp90 and Erk1/2. The relative

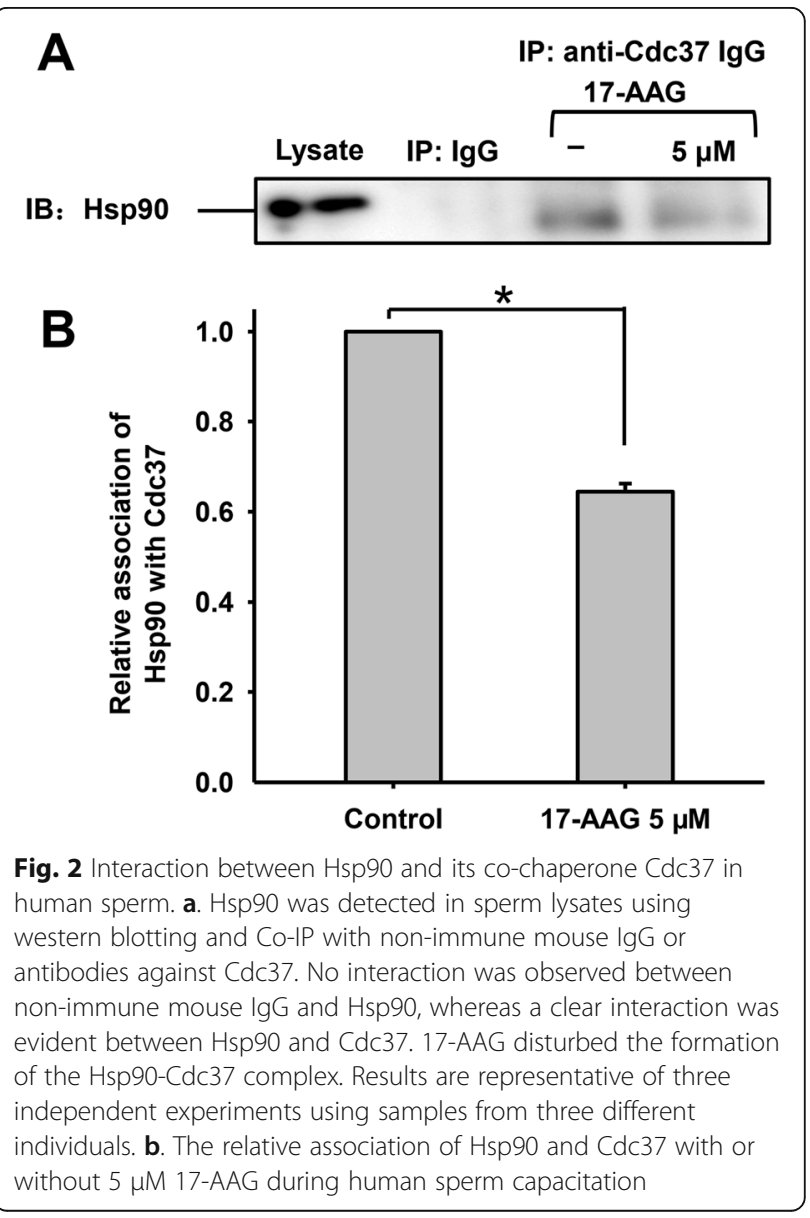




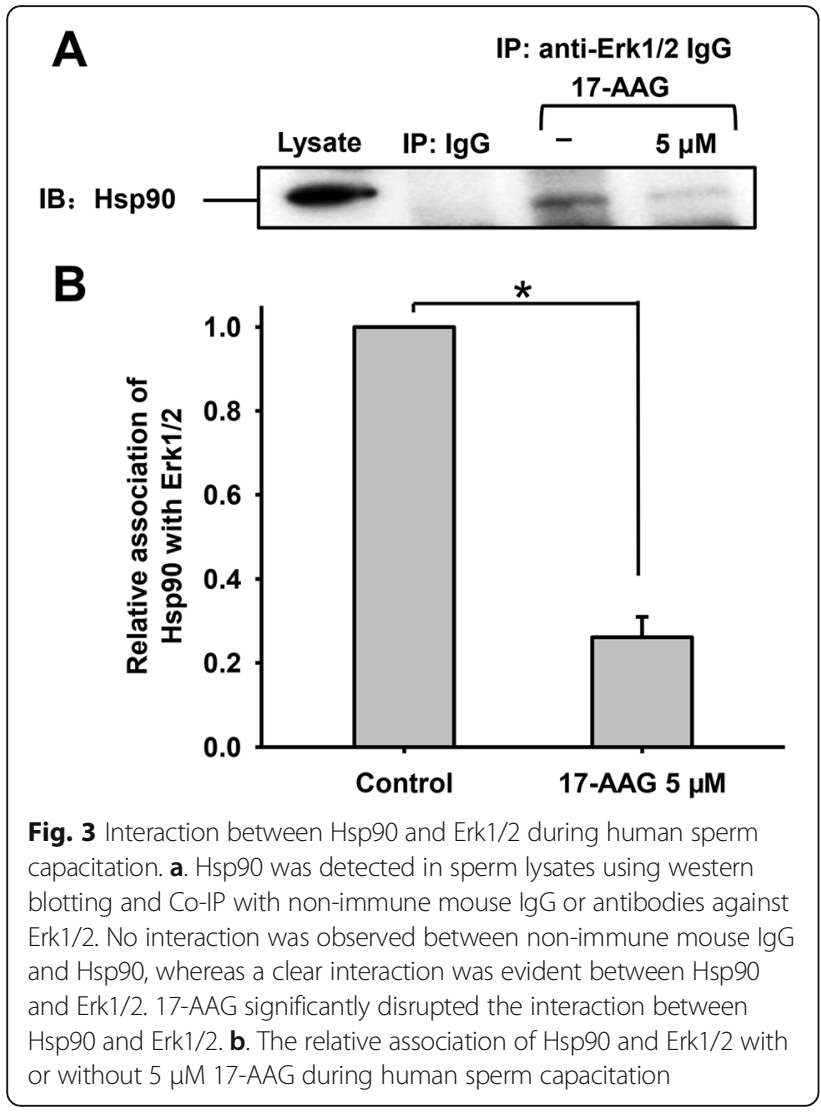

association between Hsp90 with Erk1/2 was around $25 \%$ of the control when treated with $5 \mu \mathrm{M}$ 17-AAG $\left({ }^{*} P<\right.$ 0.05) (Fig. 3b), suggesting that Erk $1 / 2$ had dissociated from the Hsp90 complex.

Erk1/2 phosphorylation at Thr202/185 and Tyr204/ 187 is required for enzyme activation [31], and phosphorylated Erk1/2 (p-Erk1/2) has been shown to promote motility, hyperactivated motility, and the acrosome reaction in human sperm. To determine how Hsp90 regulates Erk1/2 function during sperm capacitation, we examined the effects of 17-AAG on Erk1/2 and its phosphorylated form. Sperm were divided into five groups: control $0 \mathrm{~h}$, capacitation for $3 \mathrm{~h}$, treated with DMSO for $3 \mathrm{~h}$ (vehicle control), and treated with 0.5 $\mu \mathrm{M}$ or $5 \mu \mathrm{M}$ 17-AAG for $3 \mathrm{~h}$. After lysis, the proteins were resolved by SDS-PAGE and subjected to western blotting analysis. We found that the level of p-Erk1/2 decreased when treated with 17-AAG (Fig. 4a, upper), as did Erk1/2 expression after 17-AAG treatment for $3 \mathrm{~h}$ during capacitation (Fig. 4a, middle). Therefore, we examined the densitometric ratio of p-Erk1/2 to Erk1/2, finding no significant differences between the 17-AAGtreated and control groups (Fig. 4b). However, the densitometric ratio of Erk1/2 to $\beta$-tubulin differed significantly between the vehicle control (DMSO) group and sperm treated with $5 \mu \mathrm{M}$ 17-AAG (Fig. $4 \mathrm{c}, P<0.05$ ),

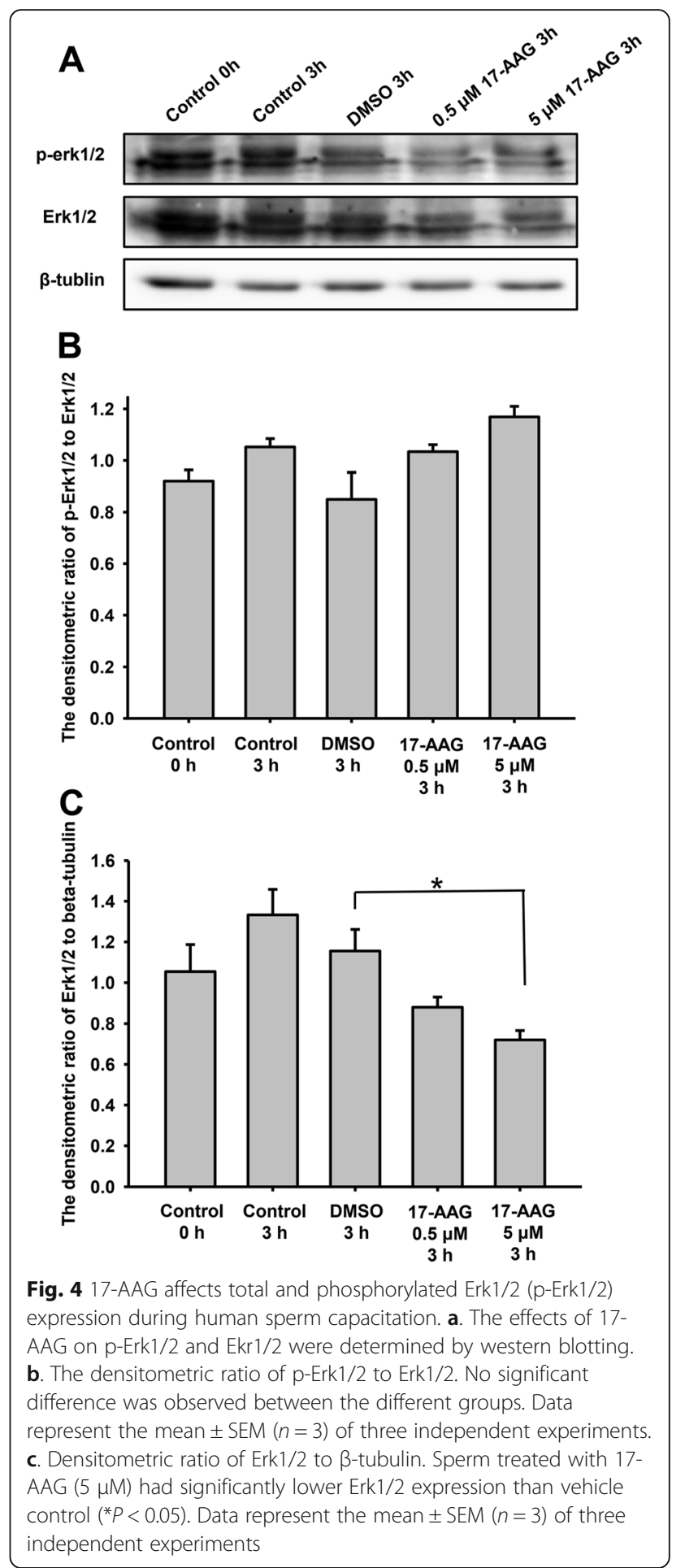

suggesting that Erk1/2 was degraded in human sperm treated with 17-AAG.

Together, these findings demonstrate that treating human sperm with 17-AAG during capacitation disrupts the interaction between Hsp90 and Erk1/2. Without the molecular chaperone Hsp90, Erk1/2 may become 
unstable and be degraded, consistent with the observed decrease in Erk1/2 expression. Since the expression level of Erk1/2 decreased when treated with 17-AAG, the level of p-Erk $1 / 2$ decreased; the enzyme activity of Erk1/ 2 also declined. Since p-Erk1/2 promotes hyperactivated motility and the acrosome reaction, 17-AAG may inhibit human sperm capacitation by interfering with Erk1/2 activity, whereas Hsp90 promotes Erk1/2 stability and kinase activation during capacitation.

\section{7-AAG causes p38 to dissociate from Hsp90 and be activated by phosphorylation}

Like Erk1/2, p38 is also located in the tail of human sperm alongside Hsp90 and Cdc37 [27]. To elucidate the mechanisms via which Hsp90 regulates p38 during human sperm capacitation, we investigated the interaction between $\mathrm{Hsp} 90$ and p38 in sperm treated with 17-AAG (Fig. 5). As expected, there was no interaction between the control IgG and Hsp90; however, Hsp90 interacted closely with p38 during sperm capacitation and the interaction declined significantly when 17-AAG was added. The relative association between $\mathrm{Hsp} 90$ and p38 was approximately $45 \%$ of the control when treated with $5 \mu \mathrm{M}$ 17-AAG (" $P<0.05)$, suggesting that p38 dissociated from Hsp90.

P38 is known to inhibit the forward and hyperactivated motility of sperm and is involved in the acrosome

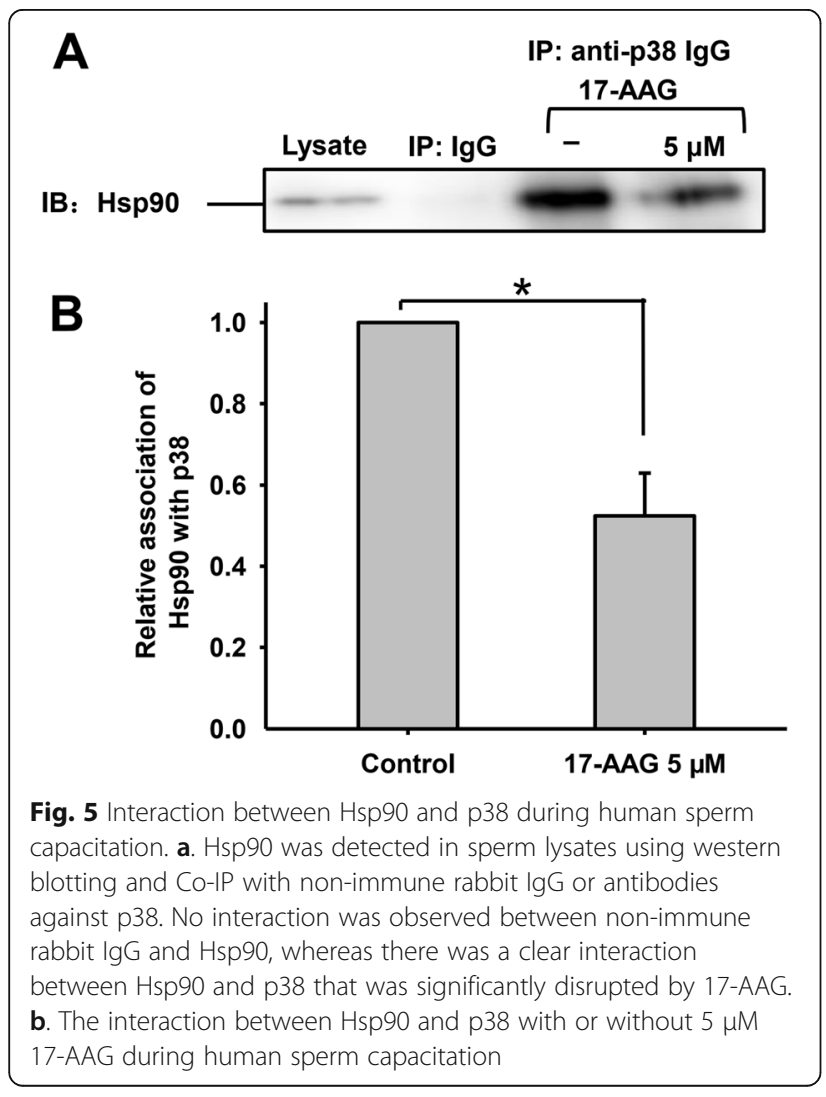

reaction during human sperm capacitation. MAPKs are activated by the phosphorylation of a Thr-X-Tyr motif by upstream kinases; in particular, p38 is activated by phosphorylation at Tyr323 and the subsequent autophosphorylation of Thr180 and Tyr182 [32]. In this study, we examined the effect of 17-AAG on p38 expression and phosphorylation using western blotting. Sperm were divided into five groups: control $0 \mathrm{~h}$, capacitation for $3 \mathrm{~h}$, treated with DMSO for $3 \mathrm{~h}$ (vehicle control), and treated with $0.5 \mu \mathrm{M}$ or $5 \mu \mathrm{M}$ 17-AAG for $3 \mathrm{~h}$. We finding that phosphorylated-p38 (p-p38) levels increased significantly after capacitation for $3 \mathrm{~h}$, while 17-AAG increased p-p38 levels further (Fig. 6a, upper) but did not change p38 expression (Fig. 6a, middle). Next, we examined the densitometric ratio between p-p38 and p38, finding that p38 was activated after capacitation for $3 \mathrm{~h}$ and that 17-AAG promoted p38 activity (Fig. 6b) but not p38 expression (Fig. 6 c).

Together, these results suggest that Hsp90 interacts with $\mathrm{p} 38$ during human sperm capacitation by suppressing its phosphorylation and inhibiting its kinase activity. When p38 dissociates from the Hsp90 complex, it is activated by phosphorylation at Thr180 and Tyr182. Since p-p38 inhibits sperm motility and hyperactivated motility during capacitation, the amplification of p38 phosphorylation by 17-AAG may further suppress sperm motility.

\section{Discussion}

Capacitation is the process that sperm undergo a series of biochemical and physiological events in the female reproductive tract to become able to fertilize an oocyte. It is a prerequisite for human sperm fertilization [31, 33]. The mechanisms of capacitation are complicated, which encompass the outflow of cholesterol, regulation of ion permeability and protein phosphorylation. After capacitation, sperm appear hyperactivation and acrosome reaction, which aids the fusion of sperm into an oocyte. $\mathrm{Ca}^{2+}$ is essential to regulate human sperm capacitation, sperm motility and acrosome reaction. At the initial stage of capacitation, intracellular increasing of $\mathrm{Ca}^{2+}$ and $\mathrm{HCO}_{3}{ }^{-}$ activate soluble adenylate cyclase (sAC), which catalyzes ATP into cAMP; cAMP subsequently activates PKA, which activates target proteins, promotes protein tyrosine phosphorylation and induces capacitation (Fig. 7) $[7,31,34]$. However, the mechanisms that act downstream of PKA during human sperm capacitation remain unclear.

Hsp90 is expressed ubiquitously in various cell types and plays critical roles by interacting with client proteins [8]. Previously, we found that Hsp90 is expressed in human sperm and is mainly localized in the neck and tail regions. By using geldanamycin, an Hsp90 specific inhibitor, we have demonstrated that Hsp90 is involved in 


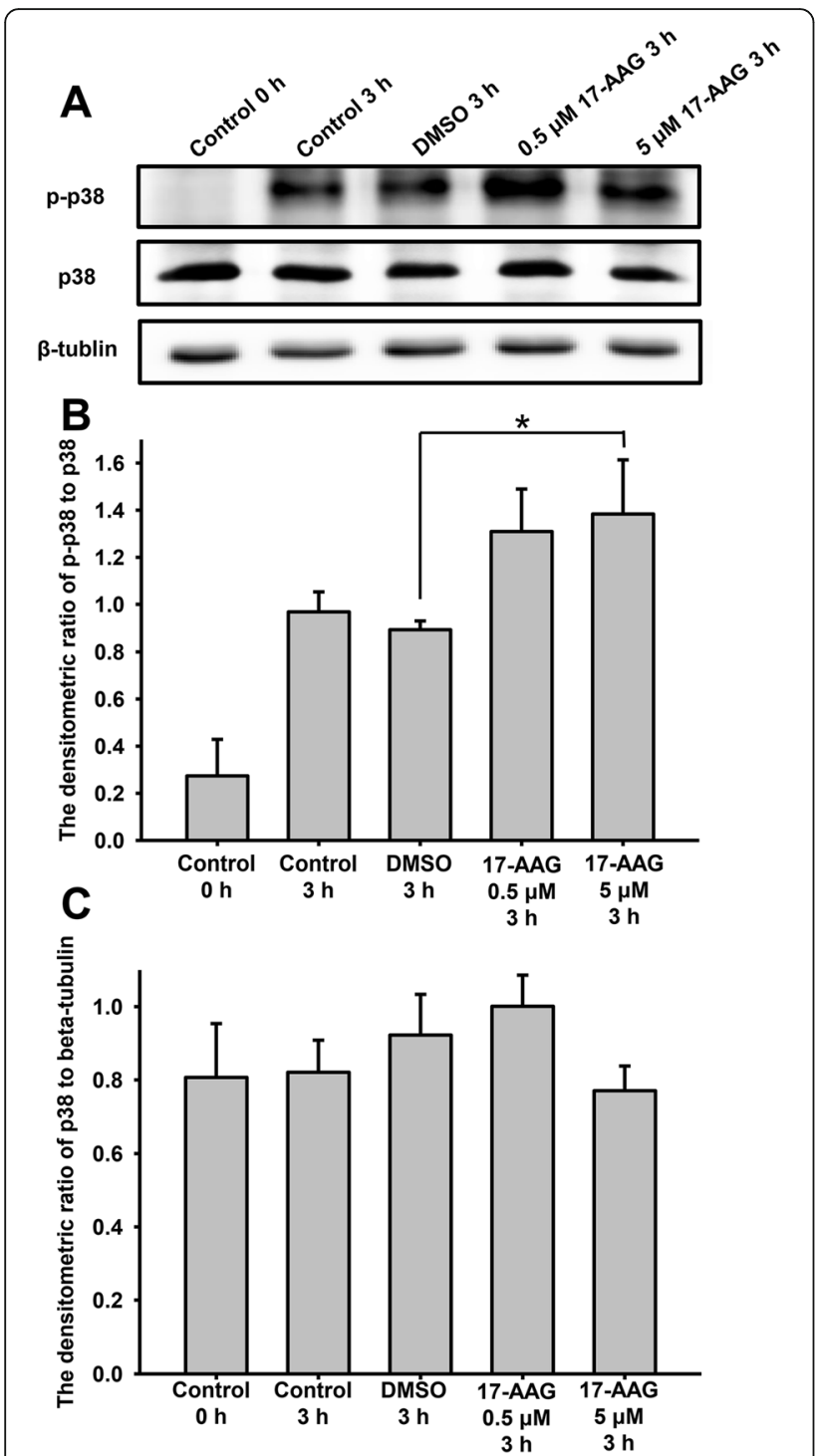

Fig. 6 17-AAG affects total and phosphorylated p38 (p-p38) expression during human sperm capacitation. a. The effects of 17AAG on p-p38 and p38 were determined using western blotting. $\mathbf{b}$ The densitometric ratio of p-p38 to p38. Sperm treated with 17-AAG $(5 \mu M)$ had significantly higher $p-p 38$ levels than vehicle control $\left({ }^{*} P<0.05\right)$. Data represent the mean $\pm \operatorname{SEM}(n=3)$ of three independent experiments. c. Densitometric ratio of p38 to $\beta$-tubulin. There was no significant difference between the different groups. Data represent the mean \pm SEM $(n=3)$ of three

independent experiments

intracellular calcium homeostasis, regulating protein tyrosine phosphorylation, sperm hyperactivated motility, and the acrosome reaction in response to progesterone [12]. Here human sperm were treated with geldanamycin derivative 17-AAG (another Hsp90 specific inhibitor) during sperm capacitation, while the procedures for sperm capacitation culture were accordance with our previous work. Consistently, we found that 17-AAG also influences the acrosome reaction and hyperactivation of human sperm, suggesting that Hsp90 regulates human sperm capacitation. However, the mechanisms still unknown.

It was previously reported that around $60 \%$ of the human kinome interacts with Hsp90 [33], with the assistance of its kinase-specific co-chaperone, Cdc37, which promotes kinase maturation by acting as an adapter and recruiting them to the Hsp90 protein complex. In many tumor cells, Cdc37 overexpression is oncogenic [15], as it mediates the recruitment of kinases to the Hsp90 system and maintains their enzyme activity. Recently, we found that Cdc37 is also expressed in human sperm in the same location as Hsp90. Hsp90 interacts with Cdc37 and is phosphorylated by PKA during human sperm capacitation [20]; therefore, we hypothesized that Hsp90 may further regulate human sperm capacitation via important kinase pathways downstream PKA with the help of Cdc37.

In this study, we demonstrated that Hsp90 and Cdc37 interact with each other during human sperm capacitation. The interaction between Hsp90 and Cdc37 is mediated by binding of the Hsp90 middle domain to an $\mathrm{N}$ terminal region of Cdc37 [14, 35]. When human sperm was treated with 17-AAG, a benzoquinone ansamycin antibiotic that specifically targets Hsp90 and interferes with its function as a molecular chaperone, levels of the Hsp90-Cdc37 protein complex decreased significantly ( $65 \%$ compared to the control) (Fig. 2). Previous studies found that 17-AAG and its analog, geldanamycin, did not disrupt the interaction between Hsp90 and Cdc37 [36, 37]; however, we observed a decrease in Hsp90 levels in the immunoprecipitated Cdc37 complex treated with 17-AAG. Previously, we showed that geldanamycin decreased Hsp90 expression in sperm in a dosedependent manner [12], while other studies have found that 17-AAG downregulates Hsp90 expression at the post-translational level in bladder cancer cells [38]. Since 17-AAG is a geldanamycin derivative with an allylamino group at position 17 of the scaffold structure and a similar biological action [38], 17-AAG may reduce Hsp90Cdc37 levels by decreasing Hsp90 expression in human sperm, thus explaining this discrepancy. Together, these findings suggest that 17-AAG reduces levels of the Hsp90-Cdc37 protein complex during human sperm capacitation, thereby affecting kinases recruited to Hsp90-Cdc37 via Cdc37.

We also found that 17-AAG significantly interrupted the interaction between Hsp90 and Erk1/2 in human sperm ( $25 \%$ compared to the control) (Fig. 3) and led to greater dissociation than between Hsp90 and Cdc37. These findings suggest that the decrease observed for the Hsp90-Erk1/2 complex was caused by both a decrease in Hsp90 expression and a disrupted interaction between Hsp90 and Erk1/2. Eckl et al. also observed that 


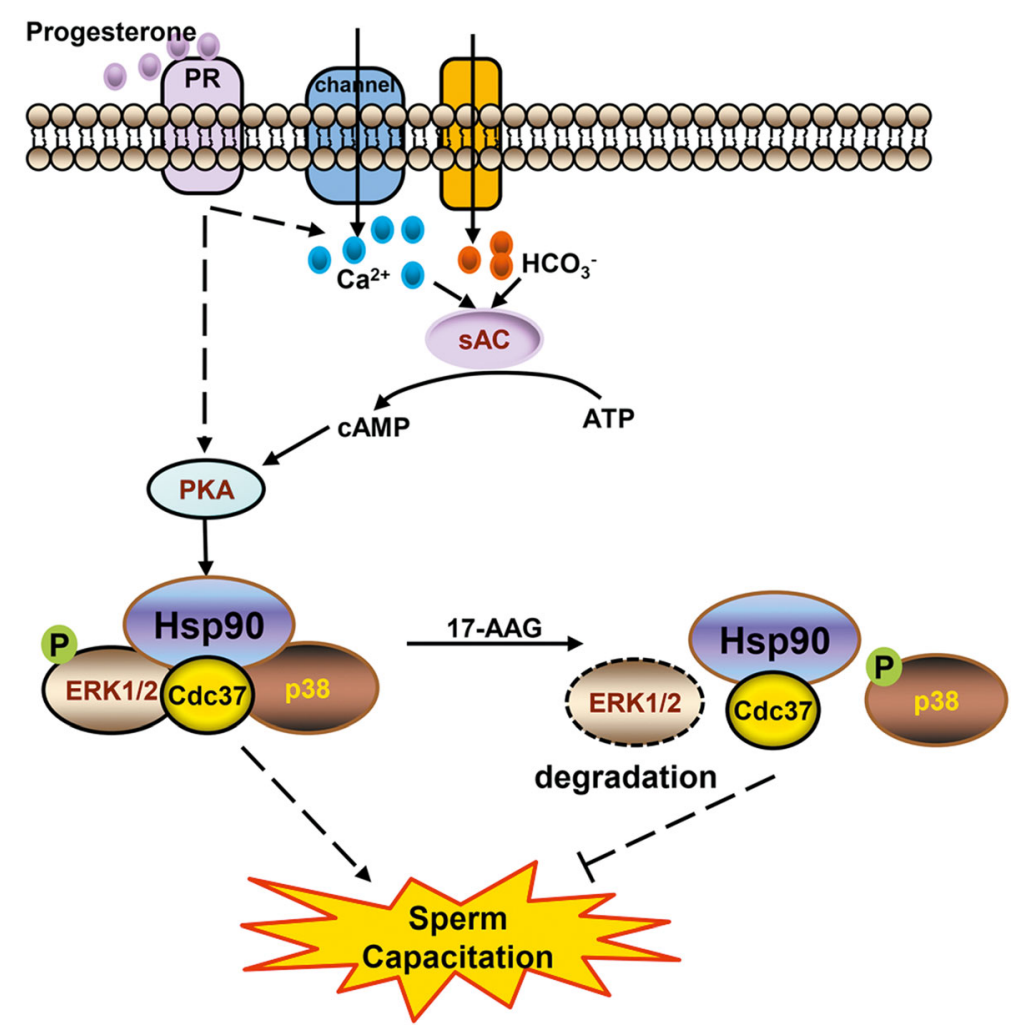

Fig. $7 \mathrm{Hsp90}$ modulates human sperm capacitation via the Erk1/2 and p38 signal pathwaysDuring human sperm capacitation, cholesterol outflow from the plasma membrane increases membrane permeability and thus the influx of $\mathrm{Ca}^{2+}$ and $\mathrm{HCO}_{3}{ }^{-}$activated soluble adenylate cyclase (SAC), which catalyzes the conversion of ATP into CAMP. Subsequently, CAMP activates CAMP-dependent protein kinase A (PKA), which activates target proteins such as Hsp90. Activated Hsp90 and its kinase-specific co-chaperone Cdc37 form a protein complex with Erk1/2, which stabilizes Erk1/2 and maintains its phosphorylation. Phosphorylated Erk1/2 is activated and promotes sperm hyperactivation and the acrosome reaction. Hsp90 and Cdc37 also form a protein complex with p38, which maintains unphosphorylated p38. Since phosphorylated p38 is activated and inhibits sperm hyperactivation, the Hsp90-Cdc37-Erk1/2-p38 complex promotes human sperm capacitation. Treatment with 17-AAG, an Hsp90 specific inhibitor, causes Erk1/2 and p38 to dissociate from the complex. Erk1/2 is subsequently degraded and dephosphorylated, whereas p38 activates itself via autophosphorylation. Ultimately, these changes inhibit human sperm capacitation

Erk2 interacts with the Hsp90-Cdc37 complex [14], which was accordance with our findings.

Following 17-AAG administration in human sperm, Erk1/2 dissociated from the Hsp90 complex and was degraded, thereby reducing Erk1/2 activation (p-Erk1/2). Studies in human urinary bladder cancer cells have also reported that total and phosphorylated Erk $1 / 2$ protein levels are reduced in a 17-AAG-dependent manner [38]; however, the levels of total Erk1/2 following 17-AAG treatment differed depending on the cell type or cell line [38-40]. Consequently, the decrease in Erk1/2 levels may depend on cell type, 17-AAG concentration, and incubation time. In this study, Hsp90 promoted the stability and activity of Erk1/2 in human sperm, while previous reports have suggested that Erk1/2 phosphorylation promotes sperm motility and acrosome reactions [28]. Therefore, 17-AAG may inhibit human sperm capacitation by disrupting the Hsp90-Cdc37-Erk1/2 complex and affecting Erk1/2 stability, thereby decreasing the levels of active phosphorylated Erk1/2.
The interaction between Hsp90 and p38 also decreased following 17-AAG administration during human sperm capacitation; however, when p38 dissociated from the Hsp90-Cdc37 complex, its phosphorylation at Thr180 and Tyr182 increased. Previously, Ota et al. demonstrated that p38 interacts with $\mathrm{Cdc} 37$ and is thereby recruited to the Hsp90-Cdc37 complex in cardiomyocytes; Hsp90 inhibition resulted in the dissociation of $\mathrm{p} 38$ from the Hsp90 complex and its subsequent activation via autophosphorylation [26]. In osteoblasts, geldanamycin and 17-AAG have been shown to significantly enhance phosphorylated p38 levels in a dose-dependent manner [41]. Collectively, these results support the possibility that 17-AAG treatment causes p38 to dissociate from the Hsp90-Cdc37 complex and activate itself via autophosphorylation in human sperm. In addition, p-p38 has been shown to inhibit sperm motility, which may explain why 17-AAG inhibited hyperactivated motility in human sperm. Although p-p38 can also promote the acrosome reaction, 17-AAG ultimately inhibited human sperm capacitation. 


\section{Conclusions}

In summary, the findings of this study suggest that the specific Hsp90 inhibitor, 17-AAG, influences human sperm capacitation by disrupting the interaction between Hsp90-Cdc37 and the MAPK kinases Erk1/2 and p38. In particular, 17-AAG inhibited capacitation by decreasing total and p-Erk1/2 levels and increasing p-p38 levels (Fig. 7). To our knowledge, this is the first study to report that Hsp90 regulates human sperm capacitation via the Erk1/2 and p38 MAPK signaling pathways.

\begin{abstract}
Abbreviations
Hsp90: Heat shock protein 90; Cdc37: Cell division cycle protein 37; MAPKs: Mitogen-activated protein kinases; Erk1/2: Extracellular signalregulated kinase 1/2; 17-AAG: 17-allylamino-17-demethoxygeldanamycin; PSA-FITC: Fluorescein isothiocyanate-conjugated Pisum sativum agglutinin; sAC: Soluble adenylate cyclase; PKA: Protein kinase A; PKC: Protein kinase C; MAP3Ks: MAP kinase kinase kinases; MAP2Ks: MAP kinase kinases; JNK1-3: CJun N-terminal kinases 1-3
\end{abstract}

\section{Acknowledgements}

We thank all donors who participated in this study.

\section{Authors' contributions}

PS, YW and YN designed the study; PS, YW, TG, KL, DZ and AL performed the experiments; PS, YW and YN analyzed the data; PS drafted the paper; all authors read and approved the submitted and final versions.

\section{Funding}

This work was supported by Natural Science Foundation of China (Nos. 81771647,81801525 and 81571426), Health Sci\&Tech Plan Project of Zhejiang Province (2018KY039, 2019KY363), Natural Science Foundation of Zhejiang Province (No. LQ17H040004), Special Project for the Research Institutions of Zhejiang Province (C11920D-04), Zhejiang Province Program for the Cultivation of High-level innovative Health talents, and start-up fund of Hangzhou Medical College (No. C11904Q-04).

\section{Availability of data and materials}

All data used during the study are available from the corresponding author by request.

\section{Declarations}

\section{Ethics approval and consent to participate}

This study was approved by the Medical Ethics Committee of the Zhejiang Academy of Medical Sciences. Informed consents were signed by healthy male donors.

\section{Consent for publication}

Not applicable.

\section{Competing interests}

The authors declare that they have no competing interests.

Received: 17 October 2020 Accepted: 23 February 2021

Published online: 04 March 2021

\section{References}

1. De Jonge C. Biological basis for human capacitation-revisited. Human reproduction update. 2017 May 1;23(3):289 - 99.

2. Bragado MJ, Gil MC, Martin-Hidalgo D, Hurtado de Llera A, Bravo N, Moreno $A D$, et al. Src family tyrosine kinase regulates acrosome reaction but not motility in porcine spermatozoa. Reproduction. 2012 Jul;144(1):67-75.

3. Andrisani A, Dona G, Tibaldi E, Brunati AM, Sabbadin C, Armanini D, et al. Astaxanthin Improves Human Sperm Capacitation by Inducing Lyn Displacement and Activation. Marine drugs. 2015 Aug 25;13(9):5533-51.
4. Strunker T, Goodwin N, Brenker C, Kashikar ND, Weyand I, Seifert R, et al. The CatSper channel mediates progesterone-induced Ca2 + influx in human sperm. Nature. 2011 Mar 17:471(7338):382-6.

5. Lishko PV, Botchkina IL, Kirichok Y. Progesterone activates the principal Ca2 + channel of human sperm. Nature. 2011 Mar 17;471(7338):387-91.

6. Xu WM, Shi QX, Chen WY, Zhou CX, Ni Y, Rowlands DK, et al. Cystic fibrosis transmembrane conductance regulator is vital to sperm fertilizing capacity and male fertility. Proc Natl Acad Sci USA. 2007 Jun;5(23):9816-21. 104(.

7. Ickowicz D, Finkelstein M, Breitbart H. Mechanism of sperm capacitation and the acrosome reaction: role of protein kinases. Asian journal of andrology. 2012 Nov; 14(6):816-21.

8. Taipale M, Jarosz DF, Lindquist S. HSP90 at the hub of protein homeostasis: emerging mechanistic insights. Nature reviews Molecular cell biology. 2010 Jul;11(7):515-28.

9. Colombo G, Paladino A, Woodford MR, Backe SJ, Sager RA, Kancherla P, et al. Chemical Perturbation of Oncogenic Protein Folding: from the Prediction of Locally Unstable Structures to the Design of Disruptors of Hsp90-Client Interactions. Chemistry. 2020 Mar 13.

10. Dunn DM, Woodford MR, Truman AW, Jensen SM, Schulman J, Caza T, et al. c-Abl Mediated Tyrosine Phosphorylation of Aha1 Activates Its Cochaperone Function in Cancer Cells. Cell reports. 2015 Aug 11;12(6):1006-18.

11. Zierer BK, Rubbelke M, Tippel F, Madl T, Schopf FH, Rutz DA, et al. Importance of cycle timing for the function of the molecular chaperone Hsp90. Nature structural molecular biology. 2016 Nov;23(11):1020-8.

12. Li K, Xue Y, Chen A, Jiang Y, Xie H, Shi Q, et al. Heat shock protein 90 has roles in intracellular calcium homeostasis, protein tyrosine phosphorylation regulation, and progesterone-responsive sperm function in human sperm. PloS one. 2014;9(12):e115841

13. Sagare-Patil V, Bhilawadikar R, Galvankar M, Zaveri K, Hinduja I, Modi D. Progesterone requires heat shock protein 90 (HSP90) in human sperm to regulate motility and acrosome reaction. Journal of assisted reproduction and genetics. 2017 Feb 24.

14. Eckl JM, Scherr MJ, Freiburger L, Daake MA, Sattler M, Richter K. Hsp90. Cdc37 Complexes with Protein Kinases Form Cooperatively with Multiple Distinct Interaction Sites. The Journal of biological chemistry. 2015 Dec 25; 290(52):30843-54

15. Pearl LH. Hsp90 and Cdc37 -- a chaperone cancer conspiracy. Current opinion in genetics \& development. 2005 Feb;15(1):55-61.

16. Pratt WB. The role of the hsp90-based chaperone system in signal transduction by nuclear receptors and receptors signaling via MAP kinase. Annu Rev Pharmacol Toxicol. 1997;37:297-326.

17. Boczek EE, Reefschlager LG, Dehling M, Struller TJ, Hausler E, Seidl A, et al. Conformational processing of oncogenic $\mathrm{v}$-Src kinase by the molecular chaperone Hsp90. Proceedings of the National Academy of Sciences of the United States of America. 2015 Jun 23;112(25):E3189-98.

18. Fang S, Fu J, Yuan $X$, Han C, Shi L, Xin Y, et al. Heat shock protein 90 regulates the stability of MEKK3 in HEK293 cells. Cellular immunology. 2009:259(1):49-55.

19. Sreeramulu S, Jonker HRA, Langer T, Richter C, Lancaster CRD, Schwalbe H. The Human Cdc37\{middle dot\}Hsp90 Complex Studied by Heteronuclear NMR Spectroscopy. J Biol Chem. 2008;284(6):3885-96.

20. Li K, Sun P, Wang Y, Gao T, Zheng D, Liu A, et al. Hsp90 interacts with Cdc37, is phosphorylated by PKA/PKC, and regulates Src phosphorylation in human sperm capacitation. Andrology. 2020.

21. Arthur JS, Ley SC. Mitogen-activated protein kinases in innate immunity. Nature reviews Immunology. 2013 Sep;13(9):679-92.

22. Nan X, Tamguney TM, Collisson EA, Lin LJ, Pitt C, Galeas J, et al. Ras-GTP dimers activate the Mitogen-Activated Protein Kinase (MAPK) pathway. Proceedings of the National Academy of Sciences of the United States of America. 2015 Jun 30;112(26):7996-8001.

23. Burotto M, Chiou VL, Lee JM, Kohn EC. The MAPK pathway across different malignancies: a new perspective. Cancer. 2014 Nov 15;120(22):3446-56.

24. Schulte TW, Blagosklonny MV, Romanova L, Mushinski JF, Monia BP, Johnston JF, et al. Destabilization of Raf-1 by geldanamycin leads to disruption of the Raf-1-MEK-mitogen-activated protein kinase signalling pathway. Molecular cellular biology. 1996 Oct;16(10):5839-45.

25. Grammatikakis N, Lin JH, Grammatikakis A, Tsichlis PN, Cochran BH. p50(cdc37) acting in concert with Hsp90 is required for Raf-1 function. Molecular and cellular biology. 1999 Mar;19(3):1661-72.

26. Ota A, Zhang J, Ping P, Han J, Wang Y. Specific regulation of noncanonical p38alpha activation by Hsp90-Cdc37 chaperone complex in cardiomyocyte. Circulation research. 2010 Apr 30;106(8):1404-12. 
27. Almog T, Lazar S, Reiss N, Etkovitz N, Milch E, Rahamim N, et al. Identification of extracellular signal-regulated kinase $1 / 2$ and p38 MAPK as regulators of human sperm motility and acrosome reaction and as predictors of poor spermatozoan quality. The Journal of biological chemistry. 2008 May 23;283(21):14479-89.

28. Li MW, Mruk DD, Cheng CY. Mitogen-activated protein kinases in male reproductive function. Trends in molecular medicine. 2009 Apr;15(4):159-68.

29. Almog T, Naor Z. The role of Mitogen activated protein kinase (MAPK) in sperm functions. Molecular and cellular endocrinology. 2010 Jan 27;314(2): 239-43.

30. Verba KA, Wang RY, Arakawa A, Liu Y, Shirouzu M, Yokoyama S, et al. Atomic structure of Hsp90-Cdc37-Cdk4 reveals that Hsp90 traps and stabilizes an unfolded kinase. Science. 2016 Jun 24;352(6293):1542-7.

31. Visconti PE, Krapf D, de la Vega-Beltrán JL, Acevedo JJ, Darszon A. Ion channels, phosphorylation and mammalian sperm capacitation. Asian journal of andrology. 2011;13(3):395-405.

32. Salvador JM, Mittelstadt PR, Guszczynski T, Copeland TD, Yamaguchi H, Appella $\mathrm{E}$, et al. Alternative p38 activation pathway mediated by T cell receptorproximal tyrosine kinases. Nature immunology. 2005 Apr;6(4):390-5.

33. Stival C, Puga Molina Ldel C, Paudel B, Buffone MG, Visconti PE, Krapf D. Sperm Capacitation and Acrosome Reaction in Mammalian Sperm. Advances in anatomy, embryology, and cell biology. 2016;220:93-106.

34. Battistone MA, Da Ros VG, Salicioni AM, Navarrete FA, Krapf D, Visconti PE, et al. Functional human sperm capacitation requires both bicarbonatedependent PKA activation and down-regulation of Ser/Thr phosphatases by Src family kinases. Molecular human reproduction. 2013 Sep;19(9):570-80.

35. Eckl JM, Rutz DA, Haslbeck V, Zierer BK, Reinstein J, Richter K. Cdc37 (cell division cycle 37) restricts Hsp90 (heat shock protein 90) motility by interaction with $\mathrm{N}$-terminal and middle domain binding sites. J Biol Chem. 2013 May;31(22):16032-42. 288(.

36. Zhang T, Hamza A, Cao X, Wang B, Yu S, Zhan CG, et al. A novel Hsp90

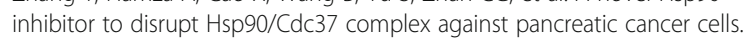
Molecular cancer therapeutics. 2008 Jan;7(1):162-70.

37. Li Y, Zhang T, Schwartz SJ, Sun D. Sulforaphane Potentiates the Efficacy of 17-Allylamino 17-Demethoxygeldanamycin Against Pancreatic Cancer Through Enhanced Abrogation of Hsp90 Chaperone Function. Nutr Cancer. 2011;63(7):1151-9.

38. Karkoulis PK, Stravopodis DJ, Margaritis LH, Voutsinas GE. 17-Allylamino-17demethoxygeldanamycin induces downregulation of critical Hsp90 protein clients and results in cell cycle arrest and apoptosis of human urinary bladder cancer cells. BMC cancer. 2010 Sep 09;10:481.

39. Georgakis GV, Li Y, Rassidakis GZ, Martinez-Valdez H, Medeiros LJ, Younes A. Inhibition of heat shock protein 90 function by 17-allylamino-17demethoxy-geldanamycin in Hodgkin's lymphoma cells down-regulates Akt kinase, dephosphorylates extracellular signal-regulated kinase, and induces cell cycle arrest and cell death. Clinical cancer research: an official journal of the American Association for Cancer Research. 2006 Jan 15;12(2):584 - 90.

40. Tamura S, Marunouchi T, Tanonaka K. Heat-shock protein 90 modulates cardiac ventricular hypertrophy via activation of MAPK pathway. J Mol Cell Cardiol. 2019 Feb:127:134-42.

41. Hioki T, Tokuda H, Nakashima D, Fujita K, Kawabata T, Sakai G, et al. HSP90 inhibitors strengthen extracellular ATP-stimulated synthesis of interleukin-6 in osteoblasts: Amplification of p38 MAP kinase. Cell Biochemistry and Function. 2020.

\section{Publisher's Note}

Springer Nature remains neutral with regard to jurisdictional claims in published maps and institutional affiliations.

Ready to submit your research? Choose BMC and benefit from:
- fast, convenient online submission
- thorough peer review by experienced researchers in your field
- rapid publication on acceptance
- support for research data, including large and complex data types
- gold Open Access which fosters wider collaboration and increased citations
- maximum visibility for your research: over 100M website views per year
At BMC, research is always in progress.
Learn more biomedcentral.com/submissions

